\title{
Decision Support System for the Stock Market using Data Analytics and Artificial Intelligence
}

\author{
Ajinkya M. Vaidya \\ Information Technology \\ Pune Vidyarthi Griha's COET \\ Pune, India
}

\author{
Nikunjkumar H. Waghela \\ Information Technology \\ Pune Vidyarthi Griha's COET \\ Pune, India
}

\author{
Sneha S. Yewale \\ Information Technology \\ Pune Vidyarthi Griha's COET \\ Pune, India
}

\begin{abstract}
The stock market is a complex, non-stationary and chaotic dynamic system. It is a popular investment platform that appeals to a wide variety of masses. While the stock market remains a significant way to earn profit, it is often considered one of the most risky forms of investment due to the underlying nature of the financial domain and a host of various factors that often elude the attention of naïve investors. The stock market is a hostile environment that demands undivided attention to the events that transpire throughout the day along with a certain consideration to the effects of the past and the implications on the future. Hence, many investors, face (or stand a risk) of failure on a daily basis. Therefore, the need of the hour is a Decision Support System (DSS) that takes into account market trends, financial analysis and strategies to identify the best time to purchase stocks and the actual stocks to purchase. This paper highlights the above concerns regarding the volatile stock market and discusses the implementation of a DSS taking into account the modern and sophisticated techniques of Data Analytics like Clustering and forecasting models like Holt-Winters. Also, the DSS uses popular supervised learning algorithm used extensively in machine learning and Artificial Intelligence, the Perceptron. While the data analytics form the initial stage of the DSS, the decision-making will be aided by the Perceptron, which would consider the results of the aforementioned analysis and various local stock market parameters and a host of statistical concepts. This will culminate in a comprehensive DSS that will assist the potential investors in the most important aspect of success in the stock market i.e. decision-making.
\end{abstract}

\section{Keywords}

Decision Support System (DSS), Data Analytics, Clustering, Holt-Winters, Supervised Learning, Machine Learning, Artificial Intelligence, Perceptron.

\section{INTRODUCTION}

A stock market is an entity that facilitates the trading between buyers and sellers. The stocks are listed on the stock exchange where they represent the entities and the multinational corporations from all around the world. It is basically a place to trade stocks.

The stock market is witness to all kinds of investors from individuals to small and large scale companies. Many companies have their stocks listed on the stock exchange signifying that the company is now public and investors can purchase a stake in it. As the investors purchase a stock, the volume decides the amount of stake that the investors have in the said company. The stock market has since become a major way for a company to raise money. Unlike other investments, results and return on investments is relatively instant which is an attractive feature of the stock market.
History has shown that the price of stocks is an important part of the overall economic activity, and can influence or be an indicator of the current social mood [1]. Usually, stock market correlates directly with the state of the economy. Hence, an important stock market means that the country is well-developed or is an equally important economy in the context of the world. The stock market reflects the current economic state along with other socio-political factors of the country. Some of the major stock exchanges in the world are New York Stock Exchange (NYSE, US), NASDAQ (US), Japan Exchange Group (JPX, Japan), National Stock Exchange of India (NSE, India) etc.

What makes a stock market unique is that even though a stock might be trading at a high rate; there is no guarantee that the stock market will remain the same. Although a number of things can help one assess a stock, no one can predict exactly how a stock will perform in the future. There is even no guarantee that a company that has a stock listed today will even remain in the business tomorrow [2]. The stock prices often fluctuate and the investors have to be extremely aware of the window of opportunity that arises to earn profit [3]. Now, this window arises randomly and investors might have to wait a long time for it. There are many such subtle facts and traits about the stock market which makes it an extremely unwelcoming environment for beginners. The huge amount of stocks listed in the exchange and the unbelievable pace at which the transaction occur render beginners catatonic. The investor is thrown into this frenzy without any guidance and just the sheer pressure on him forces him to take rash and otherwise unwise decisions [4]. Probably, at this hour, every beginner and for that matter any investor would appreciate all the help he gets in making the right decision. It is with this thought, the Decision Support System (DSS) is proposed.

\section{EXISTING SYSTEMS}

The stock market, which has been investigated by various researchers, is a rather complicated environment. Investors face higher risks compared to other form of financial investments when they invest in stock market. Many people have tried to predict the movement of share prices and beat the market but no one can really accurately predict the movement of a particular share prices for company listed in the stock exchange. No two existing systems are identical; each one provides a unique price and feature point. Hence, the problem of compatibility of data between different systems arises. All the existing systems require proper data with specific attribute from stock data. Data is rarely tested on the live market and identification of these attributes is not easy.

There has been an attempt from Information Technology (IT) professionals to exploit the stock price prediction area through the Artificial Intelligence (AI) approach. There have been many approaches in this field, including advanced techniques but no comprehensive system has been developed. The fields of Data Mining, Artificial Neural Network (ANN) and Regression Analysis have been used to attempt a comprehensive system [5] 
[6]. Along with these various Genetic Algorithms, Time Series Analysis, Fuzzy Neural Networks have also been proposed. A prototype model, Multilevel and Interactive Stock Market Investment System (MISMIS) has been also been proposed to forecast stock prices. In the current years of development in the field of data mining, it is considered that the partitioned clustering technique is well suited for analyzing stock prices. The best-known partitioning clustering algorithm is the K-means algorithm and its variants, as this algorithm is simple, straightforward and is based on the firm foundation of analysis of variances. In addition to the K-means algorithm, other algorithms such as Particle Swarm Optimization (PSO) are being proposed [7][8][9]. Particle Swarm Optimization is another computational intelligence method that has already been applied to image clustering and other low dimensional datasets. Yet, as of now no comprehensive singular system has been developed to support decision making for the Stock Market.

\subsection{MERITS OF EXISTING SYSTEMS}

The existing systems are not up to mark but they do have the following advantages:

- The partitioned clustering technique is well suited for clustering a large document dataset due to their relatively low computational requirements and increase in the gradual performance of the system [9].

- The time factor complexity of the partitioning technique is almost linear, because of which it is widely used.

- Many algorithms are simple, straightforward and are based on the firm foundation of maximizing variances.

\subsection{DEMERITS OF EXISTING SYSTEMS}

The existing systems have a number of flaws, which need to be rectified so as to build a comprehensive system capable of decision-making. Some of the disadvantages of existing systems are as follows:

- The stock market, which has been investigated by various researchers, is a rather complicated environment and normal techniques of data mining only lead us to a part of the solution.

- The various factors, local to the stock market are not considered while designing these systems, which are of prime importance while investing in the stock market.

- The existing systems are not built to suit the trading style or strategies of a particular user.

Existing system do not allow individual users to do fundamental scanning and screening of stocks.

\section{DECISION SUPPORT SYSTEM (DSS)}

A decision support system (DSS) is a computer based system that supports decision making activities. While academics have perceived the DSS as a tool to support decision-making process, DSS users also see the DSS as a tool to facilitate organizational processes [10][11]. A well constructed DSS takes into account a variety of factors like extracting raw data, a comprehensive knowledge base, support for user queries and some intuitive thinking based on the domain of the said query.

Three fundamental components of a DSS are [12]:

1. Knowledge base

2. Business Logic (the user entered query and the associated thinking)

\section{User interface.}

The proposed decision support system works in the following stages:

- $\quad$ Stage I:

- Gathering of historical prices of a given stock for predefined time interval.

- Gathering of local stock market parameters for a given stock

- $\quad$ Stage II:

○ Processing of historical prices using Data Analytics i.e. clustering.

- Interpretation of stock parameters.

- $\quad$ Stage III

$\circ$ Forecasting of Stock using Time-Series Analysis and calculation of statistical parameters

- $\quad$ Stage IV:

$\circ$ Decision-making using, the Perceptron model where the input feature vectors are the results obtained from the previous stages.

\section{STAGES OF THE DECISION SUPPORT SYSTEM (DSS)}

Stage i:

\section{Gathering Of Historical Prices And Local Stock Market Parameters}

The advent of new techniques in Artificial Intelligence has the potential to scan and make sense of large or big data. The analysis of this data has the potential to unlock trends and other previously unknown factors and important observations, which may open the door for success in the stock market [13].

The gathering of historical prices of a share for pre-defined interval can help in factoring a share into categories based on the volume traded for that stock. The historical data is freely and publically available on variety of sites like Yahoo Finance, Bloomberg, and Financial Times etc. This historical data can be crawled or collected using a hybrid crawler/parser. While collecting this data, defining the correct time interval (e.g. 1 year, 2 years etc.) is important. The categories in which a stock can be placed are Zero growth, slow growth and fast growth [8]. It is often noted that the volume traded for a stock is a primary indicator of the growth of the share. A stock that has a negligible volume represents 'zero' growth. Likewise moderately traded stock represents stagnancy or 'slowness' of the growth. A frequently traded stock reflects large volume indicating 'fast' growth.

Now, along with the volume another important factor to be considered is, the percent change in the prices of the stock per day. These indicate implied volatility of a stock. The volatility of the stock helps in deciding the fluctuations that it goes through during the day. While stocks with high prices often note bigger fluctuations than stocks with lower prices, it does not necessarily mean that the share is volatile. Hence, the volatility that is calculated is not a true indicator of the nature of the stock. The important thing to consider is that no matter how the stock fluctuates; it must exhibit more ups than downs.

Along with the historical prices of a stock, other important and often neglected aspects of stock market are the local stock parameters, which have equally important role. While the importance of these factors is lost on the naïve and amateur investors, the consideration of these factors is of utmost importance. There are various stock experts that use these factors 
as guidelines to decide the credibility of the stocks. Some of these important factors are:

- $\quad$ Price to Earnings ratio (P/E Ratio)

- $\quad$ Earnings per share (EPS)

- Cash Flow per share (CPS)

- Market Cap

- $\quad$ Profit Margin

- 52 Week High

- 52 Week Low

- 50 day Moving Average

- $\quad$ Average volume for 3 months

\section{STAGE II:}

\section{PROCESSING AND INTERPRETATION OF DATA COLLECTED IN THE PREVIOUS STAGE}

To help analyze the data collected in the previous stage i.e. the volume and the percent change in the stocks, a popular technique of Data Analytics viz. 'Clustering' is applied. Clustering is a popular technique that groups a set of objects in such a way that objects in the same group (called a cluster) are more similar (in some sense or another) to each other than to those in other groups (clusters). Clustering as such is not an automatic task, but an iterative process of knowledge discovery or interactive multi-objective optimization that involves trial and failure.

Now applying clustering to the historical prices will categorize a stock in three aforementioned categories or 'clusters'. Since, only the volume of a share is the desired feature that is to be considered while clustering, using a usual multi-dimensional clustering algorithm like ' $\mathrm{k}$ means' might yield incorrect results. A single dimension is much more special than one naively thinks, as one-dimensional data is much better behaved. In 1D, there is a local minima; but in 2D there are saddle points and such possible splitting points. Sometimes 1D clustering is referred to as segmentation or natural breaks optimization. For the clustering or the segmentation of the above mentioned volumes of the stock, 'Fixed Partition Clustering' works the best. Since, determining the clusters is possible without even the data as one already knows what value might be classified in which cluster and forming the boundaries of clusters is fixed beforehand, using fixed partition clustering would be the optimal choice.

The volume of the stock is a very common and often the most important factor considered by experts and investors alike to form the basis of investing in the market. Thus, the analyzing of the volume of stock for a defined interval will help classify the stock into the above mentioned clusters based on the growth. The popularly accepted notion is that any stock that has a volume of over 50,000 is considered a fast growing and equivalently 'safe' investment. Hence combining this knowledge in the fixed partitioning cluster will result in following clusters:

Table 1: Volume Clusters growth classification

\begin{tabular}{|c|c|}
\hline $\begin{array}{c}\text { Name of the } \\
\text { Cluster }\end{array}$ & Volume Range \\
\hline Zero Growth & $0-5000$ \\
\hline Slow Growth & $5001-50000$ \\
\hline Fast Growth & 50001 and above \\
\hline
\end{tabular}

'Jenks Natural Breaks Classification' is a preferable method to divide a stock's percent change into classes and find the maximum instances, which lie in which class. Jenks natural breaks classification method is a data clustering method designed to determine the best arrangement of values into different classes. This is done by seeking to minimize each class's average deviation from the class mean, while maximizing each class's deviation from the means of the other groups. In other words, the method seeks to reduce the variance within classes and maximize the variance between classes [14].

The method requires an iterative process. That is, calculations must be repeated using different breaks in the dataset to determine which set of breaks has the smallest in-class variance. Dividing the ordered data into groups starts the process. Initial group divisions can be arbitrary [15].

The various stock parameters collected in the first stage need to be interpreted to have a better understanding about the related stock. Each factor has its own meaning and importance and determining them helps in reaching the ultimate decision swiftly and correctly. The following is a summary of the meaning and interpretation of the collected stock parameters.

\section{- Price to Earnings ratio (P/E Ratio)}

The P/E Ratio is critical number in evaluating stocks. Simply put it is Price per share / Earnings per share. It gives an idea of how to tell if a stock is over or under value. The $\mathrm{P} / \mathrm{E}$ ratio also is often used as a primary indicator by the experts to assess the value of the company. The interpretation of $\mathrm{P} / \mathrm{E}$ ratio is summarized in this table-

Table 2: P/E Interpretation

\begin{tabular}{|c|c|}
\hline P/E Value & Interpretation \\
\hline N/A & $\begin{array}{c}\text { A company with } \\
\text { negligible earnings and a } \\
\text { company with sustained } \\
\text { losses }\end{array}$ \\
\hline $\mathbf{0 - 1 0}$ & $\begin{array}{c}\text { Either the stock is } \\
\text { undervalued or the } \\
\text { company's earnings are } \\
\text { thought to be in decline }\end{array}$ \\
\hline $\mathbf{1 0 - 1 7}$ & $\begin{array}{c}\text { P/E ratio in this range may } \\
\text { be considered fair value. }\end{array}$ \\
\hline $\mathbf{1 7 - 2 5}$ & $\begin{array}{c}\text { Either the stock is } \\
\text { overvalued or the } \\
\text { company's earnings have } \\
\text { increased. The stock may } \\
\text { also be considered a } \\
\text { growth stock }\end{array}$ \\
\hline $\mathbf{2 5 +}$ & $\begin{array}{c}\text { A company whose shares } \\
\text { have very high P/E may } \\
\text { have high expected future } \\
\text { growths in earnings or this } \\
\text { year's earnings may be } \\
\text { exceptionally low. }\end{array}$ \\
\hline & \\
\hline & \\
\hline &
\end{tabular}

- Earnings per share (EPS)

EPS is determined by the following formula: 
EPS $=($ Net Income - Dividends $) /($ Average number of shares outstanding)

Simply put, the EPS gives the estimated earnings that a share yields. Essentially a company must have a positive and preferably a large EPS.

\section{- Cash Flow per share (CPS)}

The EPS has one blind spot; it can be manipulated easily by the company. But CPS is impossible to manipulate and hence is rather popular. It gives a true account of how much cash a company really has and how effective its operations are. CPS should be positive and should always be more than EPS else it indicates manipulation of earnings by the company.

- Market Cap

Market Cap is determined by the following formula:

Market Cap $=($ Number of shares outstanding $) \times($ Price per share)

The market cap could be thought of, as the estimated price to buy the company. It is used to classify the size of company into small, large or mega etc. Basically larger the company, usually the more stable and safe it is.

\section{- Profit Margin}

Profit Margin can be calculated using the following formula:

\section{Profit Margin $=($ Net profit $) /$ Revenue Where Net profit $=($ Revenue - cost $)$}

Profit margin basically gives an indication of whether the company is yielding profits. More the profit margin more valuable a investment it is. A company with sustained profits for longer duration is a safe and reliable investment.

\section{- 52 Week High / Low}

A 52 Week High/Low factor is another popular investment factor. Typically, a stock trading near a 52 week high is considered to be safe investment. It may not break that barrier easily but it is a risk free investment. However, if it breaks a 52 high week barrier the share is expected to increase dramatically. A stock trading below it's 52 week low is not considered a valued investment and is best avoided.

\section{- 50 day Moving Average}

A 50 day Moving Average is equal to the average price that all investors have paid to obtain it over last 50 days. Once the price falls below the average, it may act as resistance level i.e. the stock may not cross that barrier easily. Typically a stock trading near or above it may be considered a fair value.

\section{- $\quad$ Average volume for 3 months}

It is daily average of the cumulative trading volume during the last three months. Hence, higher the value, safer the share and vice versa.

\section{Stage iii:}

\section{Forecasting using time series analysis and} calculationstatistical parameters

A time series is a sequence of data points, typically consisting of successive measurements made over a time interval. Time series data have a natural ordering. This makes time series analysis distinct from others, in where there is no natural ordering of the observations [16]. Time series analysis consists of analyzing the time series for extracting valuable information and possible trends from it. Time series forecasting is the use of a time series analysis to predict future values based on previous values. Time series analysis differs from other forms of analysis like Regression analysis as the former considers values that are separated over a predefined time interval and does not take into account random and skewed data. Time series analysis also often considers single dimensional data

While many techniques exists for predicting and forecasting a stock and its subsequent rise or fall, again the complexity of the market and it's innate volatility just makes this process hugely difficult and only moderately successful at best. Hence, forecasting a stock and relying on it to invest is not primarily the best way to go about it. While the statistics might be perfectly accurate, the circumstances and the socio-political issues have a huge impact on the market, which cannot be corrected via statistics. Therefore while forecasting a stock remains credible, it should only be considered as an indicator of what might happen, if things stay as they are which, obviously is never the case in the market.

Exponential smoothing is one of the time series methods, which can be applied to a time series data, either to produce smoothed data to make forecasts. In stock market, the ups and downs of a share should be considered because they are representative and helpful in figuring out the current vibe of the stock i.e. what is the current trend of the stock whether it is increasing, decreasing or is it stable for a given period. Single exponential smoothing can be used only for data without any trend or seasonal components [17]. Simple exponential smoothing does not do well when there is a trend in data. For such situations, several methods are devised under the name "Double exponential smoothing" or "Second order exponential smoothing" [18].

Holt-Winters double exponential smoothing is one of the methods, which uses a seasonal factor along with both the level and trend factor while predicting the stock price. In Holt's method, a slope component is added which itself is updated by exponential smoothing, thus the trend can be taken into account. Holt's method can be extended to deal with time series, which contain both trend and seasonal variations. The Holt-Winters method has two versions, additive and multiplicative, the use of which depends on the characteristics of the particular time series [19]. Holt-Winters model considers three basic factors while forecasting the stock viz. level, trend and seasonality. The parameters are often selected between 0 and 1 .

\section{- Level}

Level is the approximate value of a stock at any given period. It depends on the stock characteristics and also the irregularity of data has a wide effect on it.

- $\quad$ Trend

Trend is the long-term movement of a stock price in a given period without irregular effects and is a reflection of the underlying level. Trend is a continuing pattern of a stocks increase or decrease.

- Seasonality

Seasonality is a repeating pattern of stocks. It represents the increases and decreases that occur within a given period. The key here is to find the pattern or cycle after which the data set repeats. Seasonality consists of effects that are reasonable stable over a period of time.

\section{- Smoothing Factor $(\alpha)$}

It typically represents the weight given to the recent sales history (actual value). Its value varies from 0 to 1 . If it's closer to 1 , more weight is given to recent value.

- $\quad$ Trend Factor $(\beta)$ 
This parameter helps to represent the trend in the demand pattern. It's a smoothing factor to trends i.e. closer to 1 gives more weight to the recent trend.

\section{- $\quad$ Seasonality Factor $(\gamma)$}

This factor helps to adjust the forecast by applying seasonal percentage. It's again a smoothing factor to seasonal index. If the value is closer to 1 , more weight will be given to recent seasonal periods.

For the implementation of Holt-Winters in this DSS, dataset taken is the monthly average of closing prices for a pre-defined time interval. Hence, the frequency parameter for Holt-Winters is 12 . The $\alpha, \beta$ and $\gamma$ are calculated accordingly to get the closest value possible. Using Holt-Winters method we get the Forecast value by the expression:

$$
\text { Forecast }=(\text { Level }+ \text { Trend }) \times \text { Seasonality }
$$

Along with Time series analysis the following four techniques help in forecasting:

\section{- Typical Pricing}

Typical Price indicator is simply an average of each day's price. It provides a simple, single line plot of the day's average price. Some investors use TP rather than the closing price.

It is a building block of money flow index calculated by the following formula:

\section{Typical Pricing $=($ High + Low + Close $) / 3$}

\section{- Chaikin Money Flow Indicator (CMI)}

Chaikin Money Flow is based on Chaikin's Accumulation/Distribution. Accumulation and distribution in turn, is based on the premise that if the stock closes above its midpoint i.e.(High + Low) / 2 for the day, then there was accumulation that day, and if it closes below its midpoint, then there was distribution that day. Chaikin's money flow is calculated by summing the values of accumulation/distribution for defined period and then dividing by the same defined period sum of the volume [20].

\section{- $\quad$ Stochastic Momentum Index (SMI)}

The Stochastic Momentum Index finds the position of the closed price relative the high-low range's midpoint. It helps you to see where the current close has taken place relative to the midpoint of the recent high to low range based on the price change. SMI is based on Stochastic Oscillator [20]. The values of the SMI range from +100 to -100 . When the close is greater than the midpoint, the SMI is above zero, when the close is less than the midpoint, the SMI is below zero. The SMI is interpreted the same way as the Stochastic Oscillator. It is considered a buy signal when the SMI crosses above the oversold (-40) level; sell signal, when it crosses below the overbought $(+40)$ level.

\section{- $\quad$ Relative Strength Index (RSI)}

Relative Strength Index (RSI) is an oscillator comparing the magnitude of a stock's recent gains to the magnitude of its recent losses on a scale from 0 to 100 [20]. While employing the RSI it is recommended to use the levels of 70 or more as overbought and 30 or less as oversold. Generally if RSI rises above 30 it is considered as bullish for underlying stock.

\section{STAGE IV:}

\section{DECISION MAKING USING PERCEPTRON MODEL}

All the results obtained from the previous stages need to be combined to give the final verdict. Now various methods can be used to achieve this but, supervised learning and in particular, a Perceptron represents a perfect option.

A Perceptron is an algorithm used for classification of an input into one of several possible non-binary outputs [20]. Perceptron uses a linear-predictor function that considers the feature vectors and their respective weights to classify the given problem [21]. In the modern sense, the Perceptron is an algorithm that maps a vector with features or layers to a single binary value. The linear predictor function simply put is a multiplication of the value of the factor and its respective weight. The following is the equation of the Perceptron [20]-

$$
f(x)=\left\{\begin{array}{rr}
1 & \text { if } w \cdot x+b>0 \\
0 & \text { otherwise }
\end{array}\right.
$$

Hence, the results of clustering and the analysis of individual stock parameters along with the forecasting i.e. the results of previous stages are considered as feature vectors i.e. the input vectors to the Perceptron. The value of each feature is dependent on the interpretation and the 'likeness' of the actual value. Each feature is assigned a weight on the basis of the importance of that factor. For example, the clustering of the volume for a defined interval is an important factor, hence it is assigned the highest weight, but it is not the only factor that must be considered and hence this is where the Perceptron model becomes convenient. A linear predictor function is applied to the Perceptron. In short, the value of each feature vector is multiplied with its weight to give a value i.e. a dot product is taken. A threshold is decided first hand. If the value of the predictor function exceeds the threshold the Perceptron fires 1 else it fires 0 (indicating the binary nature of Perceptron). Now, if the Perceptron fires 1, it indicates that the share is desirable and vice-versa.

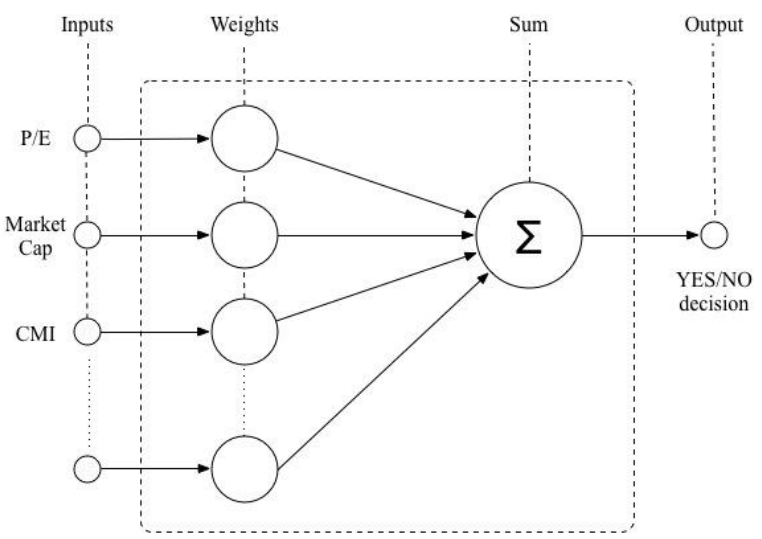

Figure 1: Modified Perceptron Model for DSS

Unlike other systems, the DSS must also provide reasoning and analysis that will help the user achieve better perspective as to why a certain decision was reached. To simply it for the user, the DSS will categorize the share into its strengths, weaknesses and intermediate factors. This visualization will help the user in easily understanding where the stock is strong and where it is wrong. Along with this, the DSS will also give a detailed analysis for each factor and the meaning of the value of each factor to help the user achieve total understanding, And as mentioned above, it will also give the forecasted price for the next period to the user. 


\section{EXPERIMENT AND RESULTS}

The above proposed DSS was implemented using Microsoft Visual Studio C\#.NET for the front end and the statistical tool $\mathbf{R}$ for analysis (viz. Clustering and Holt-Winters). The historical prices for stocks that were considered were for a period between 1 Jan 2013 to 1 Jan 2015. This data along with the required local stock parameters were gathered from the Yahoo Finance. A web crawler was used for the same. Below are attached the screenshots and the analysis that the DSS achieved. A share and the appropriate query were selected. And the analysis proceeded according to the above mentioned stages (i.e. from Stage I-Stage IV). The screenshot for the Home screen of the DSS is shown below that asks the user to input the share and select the appropriate query which would help the DSS to analyze the share accordingly-

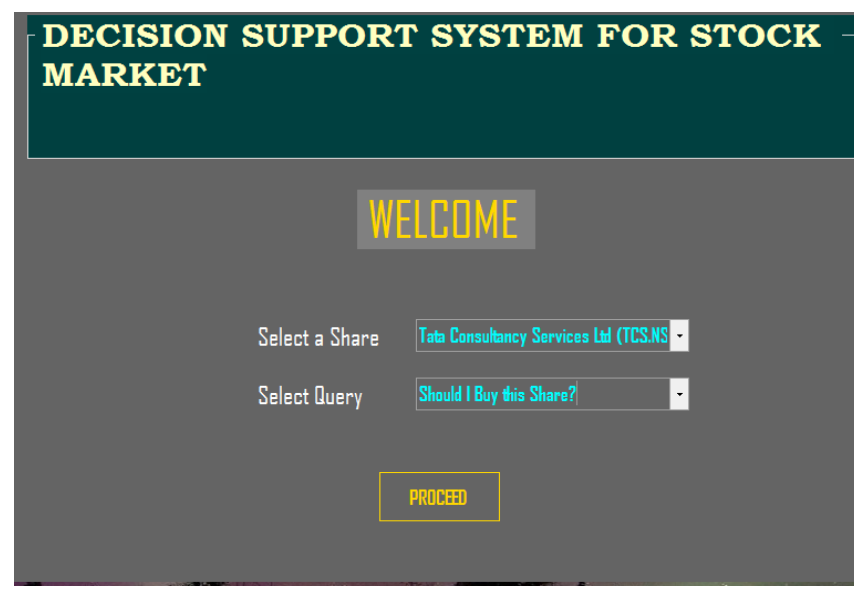

Figure 2: Selecting share and query for the DSS

The result of which was as below-

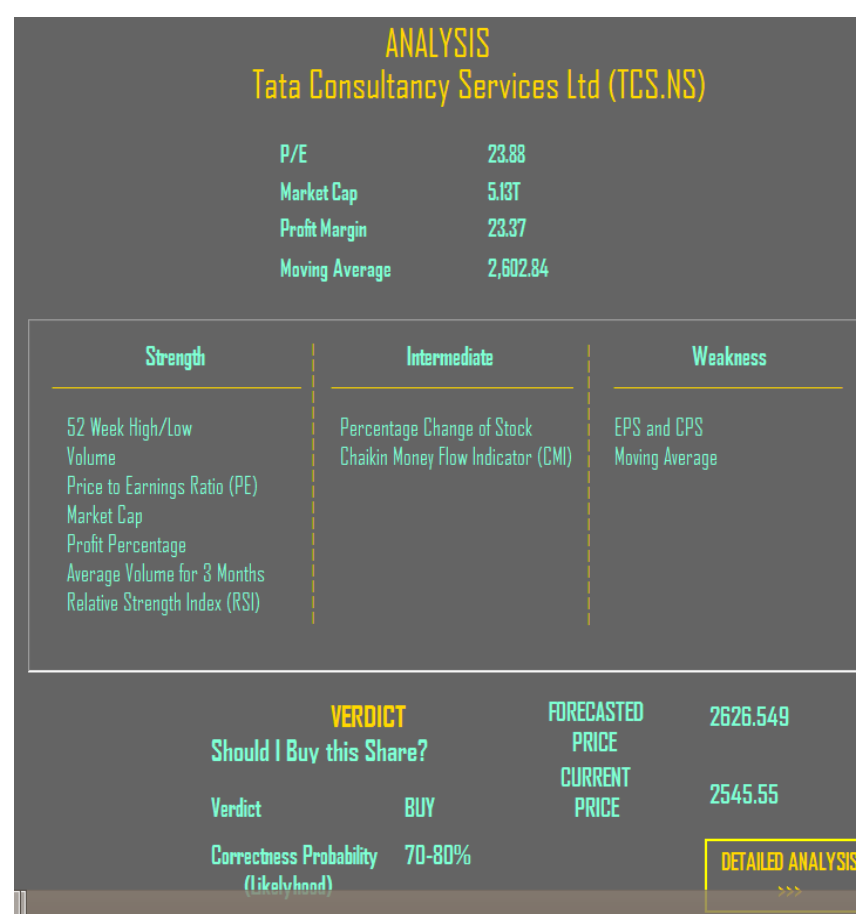

Figure 3: Analysis and Verdict by the DSS
As can be seen from the above screenshot, the DSS analyses the selected share in its strengths, intermediate factors and weaknesses. Along with it, the DSS gives the verdict as to whether the share should be bought or not (depending upon the query). Also, the surety or the likelihood of that verdict is also stated based on the strengths. Along with this, the current closing price and the forecasted value for the next month is also calculated and displayed using the Holt-Winters method. As mentioned above, the forecasted value should not be blindly adhered. Further detailed analysis is provided that explains the interpretation of each factor-

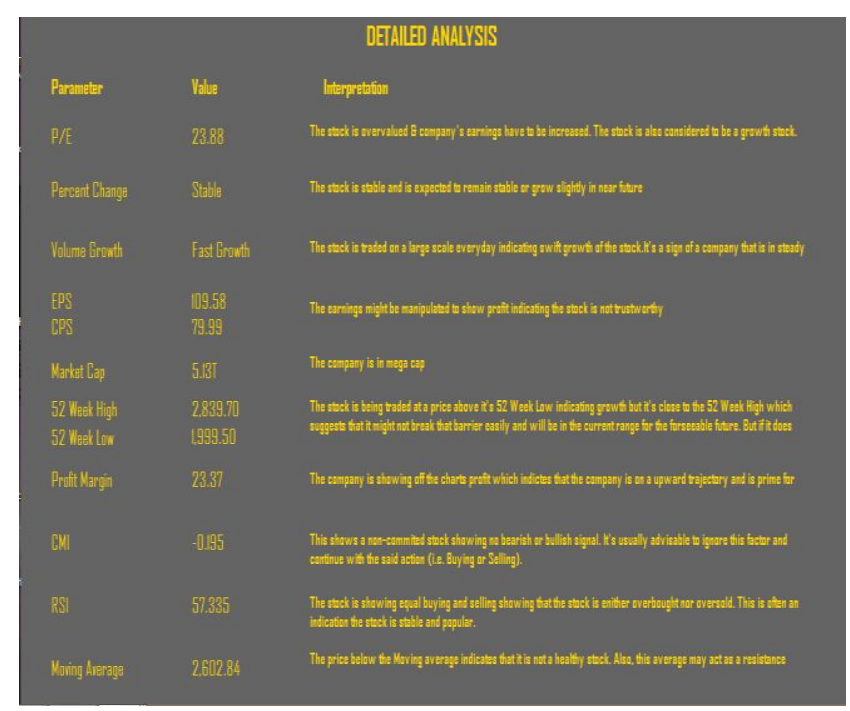

Figure 4: Detailed Analysis by the DSS

This screenshot further highlight, that each factor is explained and their importance according to the value of that factor. Any DSS should provide a detailed analysis explaining why the DSS reached the said conclusion. This condition is satisfied by the proposed DSS.

Now the above results indicate that the share TCS should be bought and these results should correspond to the average closing price of the above share for the month of February which would indicate that the DSS is analyzing correctly. Here is the closing price for each day for the month of February of TCS (gathered from Yahoo Finance)-

Table 3: Closing Prices of share TCS for the month of February

\begin{tabular}{|l|l|}
\hline Day & $\begin{array}{l}\text { Closing } \\
\text { Price }\end{array}$ \\
\hline $27-02-15$ & 2662.35 \\
\hline $26-02-15$ & 2656.45 \\
\hline $25-02-15$ & 2672.2 \\
\hline $24-02-15$ & 2704.75 \\
\hline $23-02-15$ & 2696.65 \\
\hline
\end{tabular}




\begin{tabular}{|c|c|}
\hline $20-02-15$ & 2675.55 \\
\hline $19-02-15$ & 2681.05 \\
\hline $18-02-15$ & 2635.65 \\
\hline $17-02-15$ & 2584.8 \\
\hline $16-02-15$ & 2584.8 \\
\hline $13-02-15$ & 2538.75 \\
\hline $12-02-15$ & 2462.15 \\
\hline $11-02-15$ & 2459.9 \\
\hline $10-02-15$ & 2441.15 \\
\hline $09-02-15$ & 2512.9 \\
\hline $06-02-15$ & 2575.75 \\
\hline $05-02-15$ & 2552.4 \\
\hline $04-02-15$ & 2514.3 \\
\hline $03-02-15$ & 2558.25 \\
\hline $02-02-15$ & 2514.2 \\
\hline $\begin{array}{l}\text { AVERAGE } \\
\text { CLOSING } \\
\text { PRICE - }\end{array}$ & 2584.2 \\
\hline
\end{tabular}

in the DSS. Hence, the DSS will always be subject to the market risks and such unforeseen circumstances. This is probably why no system can act as an expert system but can be a capable DSS at best. Hence these are some of the limitations that must be accepted while considering this DSS. Ultimately the DSS churns numbers, while numbers never lie, actual stock market does not quite work that way. It's this innate irrational behavior that makes it so different from any other forms of investments.

\section{CONCLUSION}

The stock market, as with any other business, is quite unforgiving of amateurs. Inexperienced investors rarely get the assistance and support they need. One of the major facts about the stock market remains that it is highly lucrative investment but one where there is absolutely no guidance and a plethora of inexperienced and naive investors. Nothing in the stock market it stagnant, changes take place rapidly and many a times the reason of them is seemingly innocuous. Also many systems go as far as predicting trends in the markets but refrain from providing guidelines to support decision making. The proposed DSS considers all the facets including the use of Data Analytics of historical prices and also the local stock market parameters, which are often excluded and ignored in many existing systems. Along with these, the DSS also takes into account forecasting of stocks, understanding the limited degree of correctness it will have. The most important observation, that many experts agree with, is that success in the stock market is never dependent on a single factor, it's an amalgamation of various factors which is why, this DSS not only considers one but many such factors. To provide the final decision, a supervised learning technique of Perceptron is considered. All the above-mentioned factors are assigned a weight on their importance and a summation is calculated to take the final decision. The ultimate aim of the DSS is to provide some insight to the end user as to why a certain conclusion is reached and help his decision making process. As mentioned above, the lack of interpretation of news and current market conditions remains an aspect for the future scope of this DSS. It will require a tremendous amount of NLP and associated profiling to determine the context and relevance to the decisions. This aspect, although important, is complicated and ripe with research opportunities. Hence, this should logically be the extension to this DSS.

The predicted (forecasted) value by the DSS is $\mathbf{2 6 2 6 . 5 5}$, which even though is not really accurate; it still captures the overall trend that the share's price is increasing which is what is intended. Also, the overall trend, which is upward, indicates that the share must be bought earlier. This is what the DSS told the user; with the surety and likeliness of $70-80 \%$ which again proves that the DSS is giving sound advices. Similarly, the DSS can work for any share as it considers all the important factors and also does relevant and important analysis.

\section{LIMITATIONS}

The proposed Decision Support System (DSS) takes into account variety of attributes including the result of data analytics and the interpretation of local stock market parameters and factors. In spite of what seems like a fairly straightforward process, the stock prices often plummet and skyrocket equally but there is no definite reason for this. Many times, the market seems to react irrationally to economic and financial news [22]. Hence, correcting the DSS for this factor seems to be a very obvious yet utterly difficult task. It will not only involve interpreting the news but also the current socio-economic state, which is not possible without the extensive use of Natural Language Processing (NLP). The current DSS is not equipped with this ability and incorporating it might be in the interest of a future scope but often things are more subtle than that; the stock market is often influenced by current political situations, mass reaction to socio-economic news. It is not only difficult but also virtually improbable to correct for this behavior and then incorporate this

The DSS assumes that the market is pretty tough to predict and it therefore provides a thorough analysis to the end user to assist him in the final decision. The need of the hour in the field of stock market is to help the investor, whether experienced or inexperienced, by assisting him, especially by exploiting the modern and the highly sophisticated techniques of Data Analytics and Artificial Intelligence.

\section{REFERENCE}

[1] Cutler, D. Poterba, J. \& Summers, L. (1991). "Speculative dynamics". Review of Economic Studies 58 (3): 520-546.

[2] Mandelbrot, Benoit \& Hudson, Richard L. (2006). The Misbehavior of Markets: A Fractal View of Financial Turbulence, annoted. Basic Books. ISBN 0-465-04357-7.

[3] Taleb, Nassim Nicholas (2008). Fooled by Randomness: The Hidden Role of Chance in Life and in the Markets, 2nd ed. Random House. ISBN 1-4000-6793-6.

[4] Tversky, A. \& Kahneman, D. (1974). "Judgment under uncertainty: heuristics and biases". Science 185 (4157): 1124-1131.

[5] Lewis-Beck, Michael S. (1995). Data Analysis: an Introduction, Sage Publications Inc, ISBN 0-8039-5772-6 
[6] Vance (September 8, 2011). "Data Analytics: Crunching the Future". Bloomberg Businessweek. Retrieved 26 September 2011.

[7] B. Uma Devi, D. Sundar, Dr. P. Alli. (2011). A Study on Stock Market Analysis for Stock Selection - Naïve Investor's Perspective using Data Mining Technique. International Journal of Computer Applications (0975 8887) Volume 34- No.3,

[8] R B. Parihar, R V. Argiddi. (2011). An Optimized Approach to Analyze Stock market using Data Mining Technique- Proceedings published by International Journal of Computer Applications (IJCA) International Conference on Emerging Technology Trends (ICETT).

[9] Aurangzeb Khan, Khairullah Khan. Frequent Patterns Mining of Stock data using Hybrid Clustering Association Algorithm, University Technology PETRONAS.

[10] Keen, Peter; (1980),"Decision support systems: a research perspective."Cambridge, Mass: Center for Information Systems Research, Alfred P. Sloan School of Management.

[11] Sprague, R; (1980). "A Framework for the Development of Decision Support Systems.” MIS Quarterly. Vol. 4, No. 4, pp.1-25.

[12] Power, D. J. (2002). Decision support systems: concepts and resources for managers. Westport, Conn., Quorum Books.
[13] Bernhard Warner (April 25, 2013). "'Big Data' Researchers Turn to Google to Beat the Markets". Bloomberg Businessweek. Retrieved August 28, 2013.

[14] Jenks, George F. 1967. "The Data Model Concept in Statistical Mapping", International Yearbook of Cartography 7: 186-190.

[15] ESRI FAQ, What is the Jenks Optimization method?

[16] Lynwood A. Johnson Douglas C. Montgomery and John S. Gardiner (1990). Forecasting and Time Series Analysis. McGraw-Hill, Inc, 2nd Edition

[17] Average and Exponential Smoothing Models | Duke University.

[18] Prajakta S. Kalekar. Time series Forecasting using HoltWinters Exponential Smoothing | IIT Bombay

[19] Chatfiel Yar. The Statistician (1988). "Holt-Winters Forecasting: Some Practical Issues"

[20] Rosenblatt, Frank (1957), The Perceptron--a perceiving and recognizing automaton. Report 85-460-1, Cornell Aeronautical Laboratory.

[21] Liou, D.-R.; Liou, J.-W.; Liou, C.-Y. (2013). "Learning Behaviors of Perceptron". ISBN 978-1-477554-73-9. iConcept Press.

[22] Shiller, Robert (2005). Irrational Exuberance (2d ed.). Princeton University Press.ISBN 0-691-12335-7. 